\title{
Sensory Quality Characteristics of Gluten-Free Products Prepared with Germinated Quinoa (Chenopodium quinoa Wild)
}

\author{
M. Naga Sai Srujana ${ }^{1}$, B. Anila Kumari ${ }^{1 *}$, K. Uma Maheswari ${ }^{1}$, \\ K.B. Suneetha Devi ${ }^{2}$ and W. Jessie Suneetha ${ }^{1}$ \\ ${ }^{1}$ Department of Foods and Nutrition, Professor Jayashankar Telangana State Agricultural \\ University, Rajendranagar, Hyderabad, 500030, Telangagna, India \\ ${ }^{2}$ Department of Agronomy, College of Agriculture, PJTS Agricultural University, \\ Rajendranagar, Hyderabad, 500030, Telangagna, India \\ *Corresponding author
}

\begin{tabular}{|c|c|}
\hline & A B S T R A C T \\
\hline & Germination can be used to improve the sensory properties of cereal and \\
\hline & amounts of protein of a high nutritional value. This study examined the \\
\hline $\begin{array}{l}\text { Germinated } \\
\text { quinoa, Laddu, } \\
\text { chapathi, Low } \\
\text { gluten products. }\end{array}$ & $\begin{array}{l}\text { effects of germinated quinoa substitutions on at various proportions on } \\
\text { sensory properties of traditional recipes of India ladoo (sweet) and } \\
\text { chapathies (unleavened Indian flat bread). Five types of formulations of } \\
\text { products were prepared with germinated quinoa flour ranging from } 25,50 \text {, }\end{array}$ \\
\hline Article Info & 75 and $100 \%$. These products were evaluated for sensory attributes. Laddu \\
\hline $\begin{array}{l}\text { Accepted: } \\
27 \text { June } 2017 \\
\text { Available Online: } \\
10 \text { August } 2017\end{array}$ & $\begin{array}{l}\text { prepared with } 100 \% \text { ragi flour, chapathi prepared with } 50 \% \text { of wheat flour } \\
\text { and } 50 \% \text { of Jowar flour was served as control. Sensory data indicated that } \\
\text { the ladoo and chapathi with up to } 25 \% \text { of germinated quinoa flour were }\end{array}$ \\
\hline & mean score for overall acceptability. \\
\hline
\end{tabular}

\section{Introduction}

Quinoa (Chenopodium quinoa Wild), a pseudo-cereal of Andean region, has received an increasing scientific and commercial attention in recent years, due to exceptional nutritional value of its seeds, associated to high protein quality and content, good balanced amino acid composition, high level of polyunsaturated fatty acids (Laus et al., 2017). The increasing consumer demand for foods that combine additional benefits in addition to common nutrients imposes on the food industry a need for advances in ingredients and formulations, particularly for the production of functional foods (Falguera et al., 2012). In recent years, a new trend in nutrition is the consumption of germinated seeds. Sprouting is an important method for not only increasing nutritional and functional value of seeds it also improve the sensory properties of cereal and pseudo-cereal grains.

Refined carbohydrates, such as white rice and white flour, are the mainstay of the modern Asian Indian diet, and may contribute to the 
rising incidence of type 2 diabetes and cardiovascular disease in this population. Prior to the 1950s, whole grains such as amaranth, barley, brown rice, millet, and sorghum were more commonly used in Asian Indian cooking. These grains and other nonIndian grains such as couscous, quinoa, and spelt are nutritionally advantageous and may be culturally acceptable carbohydrate substitutes for Asian Indians (Dixit et al., 2012).

Along with nutritional benefits, many health benefits are attributed to quinoa seeds, such as decreasing plasma cholesterol levels, stimulating the immune system, antitumor activity, reducing blood glucose levels, and improving conditions of hypertension and anemia (Caselato-Sousa and Amaya-Farfán, 2012).

In Asia, the Indian diet finds in quinoa grain a culinary acceptable high protein, high fiber, alternative to wheat, and easy to incorporate into the traditional foods. Laddu is a ballshaped sweet popular in Indian Subcontinent. Laddu is made of flour and sugar/ jaggery with other ingredients that vary by recipe. It is often served at festive or religious occasions. Common flours used for ladoo include besan (chickpea flour), rava (wheat semolina) and ground coconut (Naidu et al., 2013).

Development of traditional sweet like ladoo using combination of millets and sprouted quinoa would signify the effective utilization and optimization of gluten free grains and also promotes the traditional values that are native of the country.

Sweets could be consumed anywhere and anytime and are acceptable by the consumers. Hence the product developed; multi-grain ladoo would be a consumer acceptable propitious low cost nutritious traditional sweet.
With the changing demographics and ethnic character of the world population, various kinds of flatbreads are increasing in popularity. Recently many of the fast food chains have success in introducing flatbread wraps. Wheat is the common ingredient of most flatbreads. Wheat flatbreads made on a griddle "Chapatti, Phulka or Roti", oven baked "Naan", pan fried "Paratha" (Kahlon and Chiu, 2014). Chapati, an unleavened flat bread of Indian origin is popular in majority of the households in Asia. Basically, chapati is prepared using whole wheat flour. It is baked at high temperature for a short time period to cause rapid steam formation and eventually results in puffing of the chapati (Cheng and Bhat. 2015). In view of the nutritional and agronomic benefits of qunioa, laddu and chapathies were prepared from the composite flour containing various proportions of the germinated quinoa flour. The purpose of this study was to determine the sensory attributes of germinated quinoa flour-substituted traditional Indian recipes.

\section{Materials and Methods}

\section{Procurement of raw materials}

Quinoa (One of the accession numbers of EC series of quinoa seeds) a new variety developed at Professor Jayashankar Telangana State Agricultural University, Rajendranagar, Hyderabad was procured from Department of Agronomy, College of Agriculture, PJTSAU, Rajendranagar, Hyderabad. All the other ingredients used for the study like jaggery, ragi flour, ghee were obtained from local markets.

\section{Processing of germinated quinoa flour}

To prepare dehulled germinated quinoa, 250 gm of quinoa grain was milled in a sheller rubber roller by centrifugal force. Husk was separated and dehulled grain was collected. 
The dehulled grain was cleaned and soaked in distilled water for $10 \mathrm{hrs}$ and spread on wet laboratory paper in trays and covered with the same wet paper to hydrate the seeds by capillarity. Trays were incubated at $20^{\circ} \mathrm{C}$ in a dark chamber for $4 \mathrm{hrs}$. Then the samples were taken and dried at $50^{\circ} \mathrm{C}$ in a tray drier to constant weight. Dried sprouts were then milled using a grinder and obtained flour was stored in plastic bags in desiccators at $4^{\circ} \mathrm{C}$.

Good quality gluten free products continue to be in demand and the production of laddu from non- conventional raw materials is a major challenge. Thus the present study was carried out to develop a product with combinations of other grain flours and dehulled germinated quinoa flour and subjected to sensory evaluation.

Ladoo with dehulled germinated quinoa flour and ragi were prepared by roasting flours separately on a low flame through continuous stirring until a nice aroma developed, removed and set aside to cool. Powdered jaggery was blended thoroughly with the roasted flour of ragi and germinated quinoa. The ghee was melted and kept aside to cool. Flour mixed with jaggery was rolled to balls by adding melted ghee. Controlled sample of ragi was prepared by following the same procedure. Composition of the ladoo prepared with germinated quinoa flour and ragi is given in table 1 .

\section{Preparation of chapathi}

Good quality low glycemic products continue to be in demand. Thus the present study was carried out to develop a product with three different combinations of wheat, jowar and germinated quinoa flour. Four different compositions of chapatti's were prepared and subjected to sensory evaluation. The chapatti's been prepared with Wheat, Jowar and germinated quinoa flour in four different compositions i.e.12.5:75:12.5; 25:50:25; 37.5:25:37.5 with a control sample of chapatti's prepared with Wheat and Jowar flour in the composition of 50:50.

Chapatti with germinated quinoa flour incorporated multigrain atta (wheat, Jowar, DGQ) was prepared by moistening composite flour through continuous kneading to desired soft texture. The dough was kept aside for ten minutes. Divided the dough into small balls, and diped them into flour, press with a roller pin until the balls resemble thin, round pancakes. Heated tawa over medium heat and roasted each chapatti on both sides.

\section{Sensory evaluation of products}

A semi-trained panel of 15 members from PGRC, PJTSAU using 9 point hedonic scale evaluated the quinoa products for colour, texture, flavour, taste and overall acceptability. Scores were based on a hedonic scale of 1 to 9 where: 1=I dislike extremely (very bad) and $9=$ I like extremely (excellent) (Meilgaard et al., 1999). The samples were presented in plates coded with three digit numbers in individual booths in sensory evaluation lab. Panelists rinsed their mouth with water after testing each sample.

\section{Statistical analysis}

All the analysis was performed in replications and the results were presented as mean \pm standard deviation. Difference between the variables was tested for significance by (ANOVA) using SAS version 9.1.

\section{Results and Discussion}

\section{Sensory acceptability of laddu}

Sensory rating of ladoo for colour showed that control sample CRL (7.20) ranked at top due to excellent appearance followed by RQ1 
(6.73), RQ2 (6.06), RQ3 (5.45) while minimum mean score of colour was observed for RQ4 (5.20). The mean scores of colour for ladoo declined from 7.20 to 5.20 with increasing level of substitution of germinated quinoa flour.

Mean sensory scores for flavor of ladoo decreased from 7.26 to 5.06. Sensory acceptability of ladoo is shown in figure 3 revealed that the control sample CRL had highest mean score for flavor (7.26) followed by RQ1 (6.20), RQ2 (5.46), RQ3 (5.25) while RQ4 (5.06) had least mean score for flavor.

Mean sensory score for taste of ladoo varied from 8.00 to 4.00. Sensory acceptability of ladoo is shown in figure 3 revealed that the control sample CRL had highest mean score for taste (8.00) followed by RQ1 (6.53), RQ2 (5.20), RQ3 (4.89) while RQ4 (4.00) had least mean score for taste.

Mean sensory score for texture of ladoo varied from 8.06 to 5.73. Sensory acceptability of ladoo is shown in figure 3 revealed that the control sample CRL had highest mean score for texture (8.06) followed by RQ1 (7.26), RQ2 (6.53), RQ3 (6.02) while RQ4 (5.73) had least mean score for texture. Texture plays an important role in the selection of product from point of consumer.

Mean sensory score for overall acceptability of ladoo varied from 8.20 to 5.13. Sensory acceptability of ladoo is shown in figure 3 revealed that the control sample CRL had highest mean score for overall acceptability (8.20) followed by RQ1 (7.80), RQ2 (6.20), RQ3 (5.79) while RQ4 (5.13) had least mean score for overall acceptability. 100\% quinoa ladoo had least scores of overall acceptability of ladoo.

\section{Sensory acceptability of chapathi}

Sensory rating of chapathi for colour showed that control sample C1 (7.60) ranked at top due to excellent appearance followed by $\mathrm{C} 2$ (7.20), C3 (6.93) while minimum mean score of colour was observed for $\mathrm{C} 4$ (5.53). The mean scores of colour for chapathi declined from 7.60 to 5.53 with increasing level of substitution of germinated quinoa flour.

Mean sensory scores for flavor of chapathi decreased from 8.06 to 6.33. Sensory acceptability of chapathi is shown in figure 4 revealed that the control sample $\mathrm{C} 1$ had highest mean score for flavor (8.06) followed by C2 (7.33), C3 (6.60) while C4 (6.33) had least mean score for flavor.
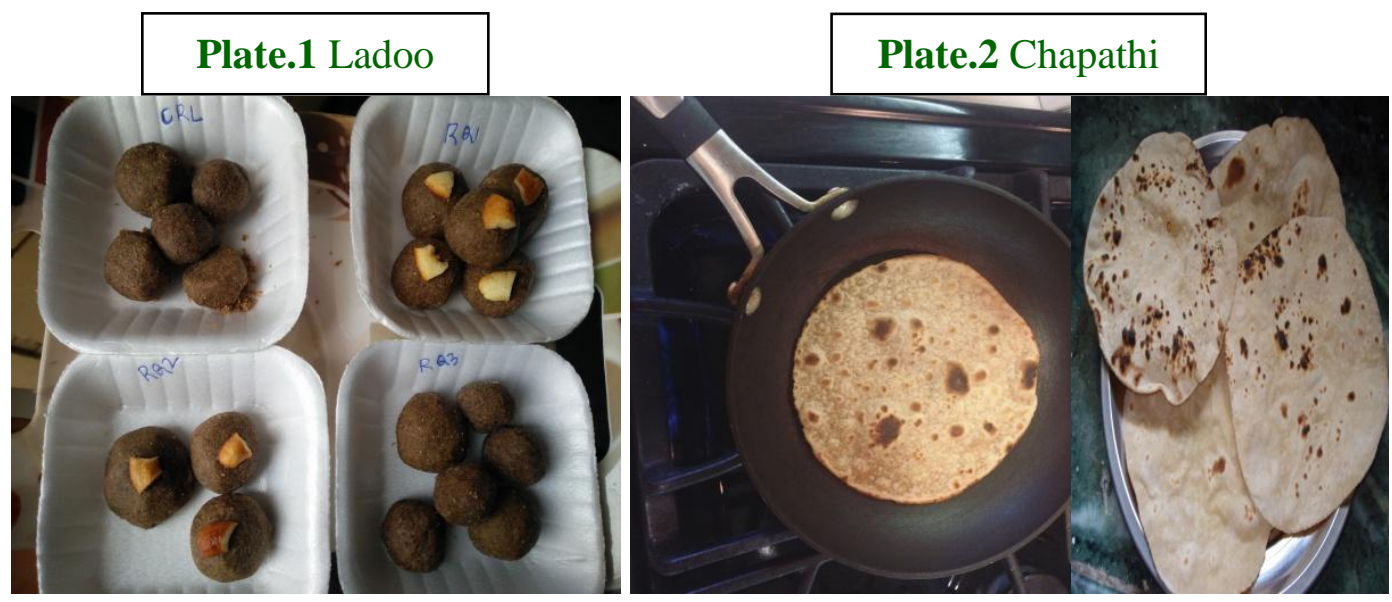
Fig.1 Flow chart for preparation of ladoo

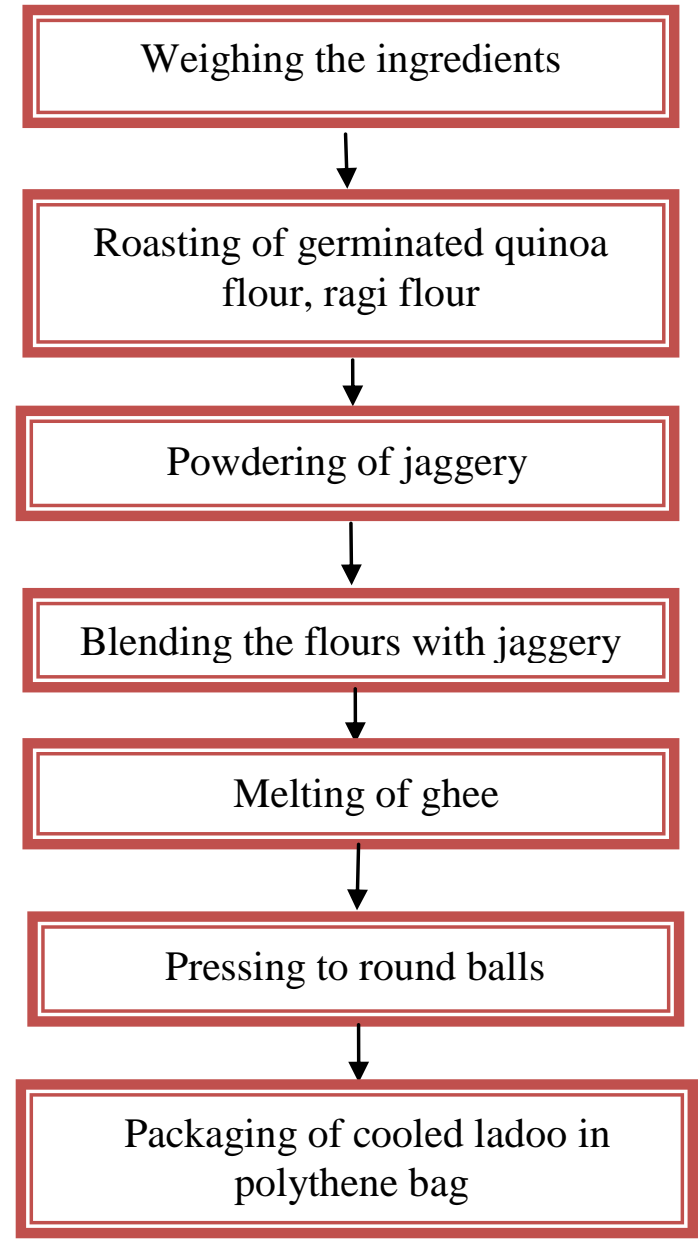

Fig.2 Flow chart for preparation of chapathi

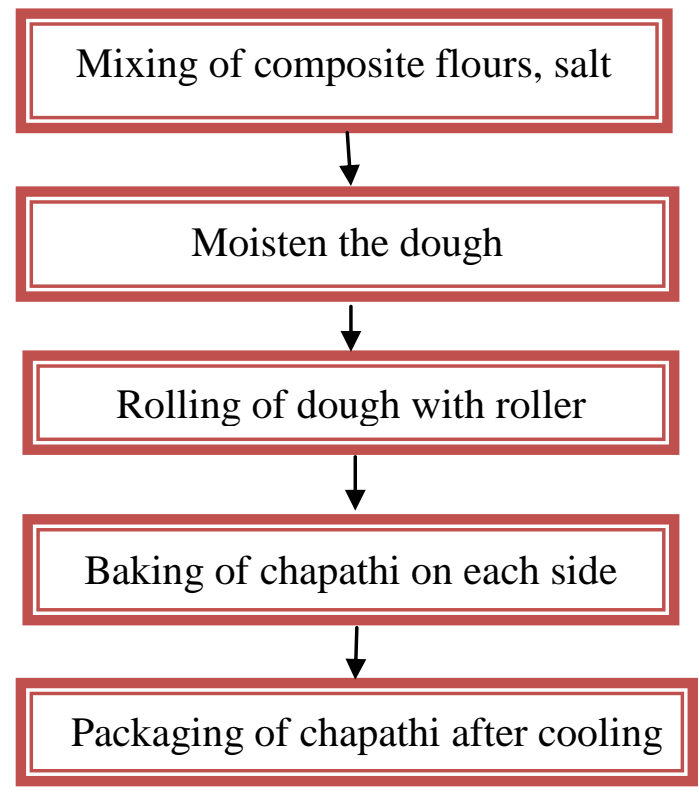


Fig.3 Sensory scores of laddu prepared with germinated quinoa and ragi

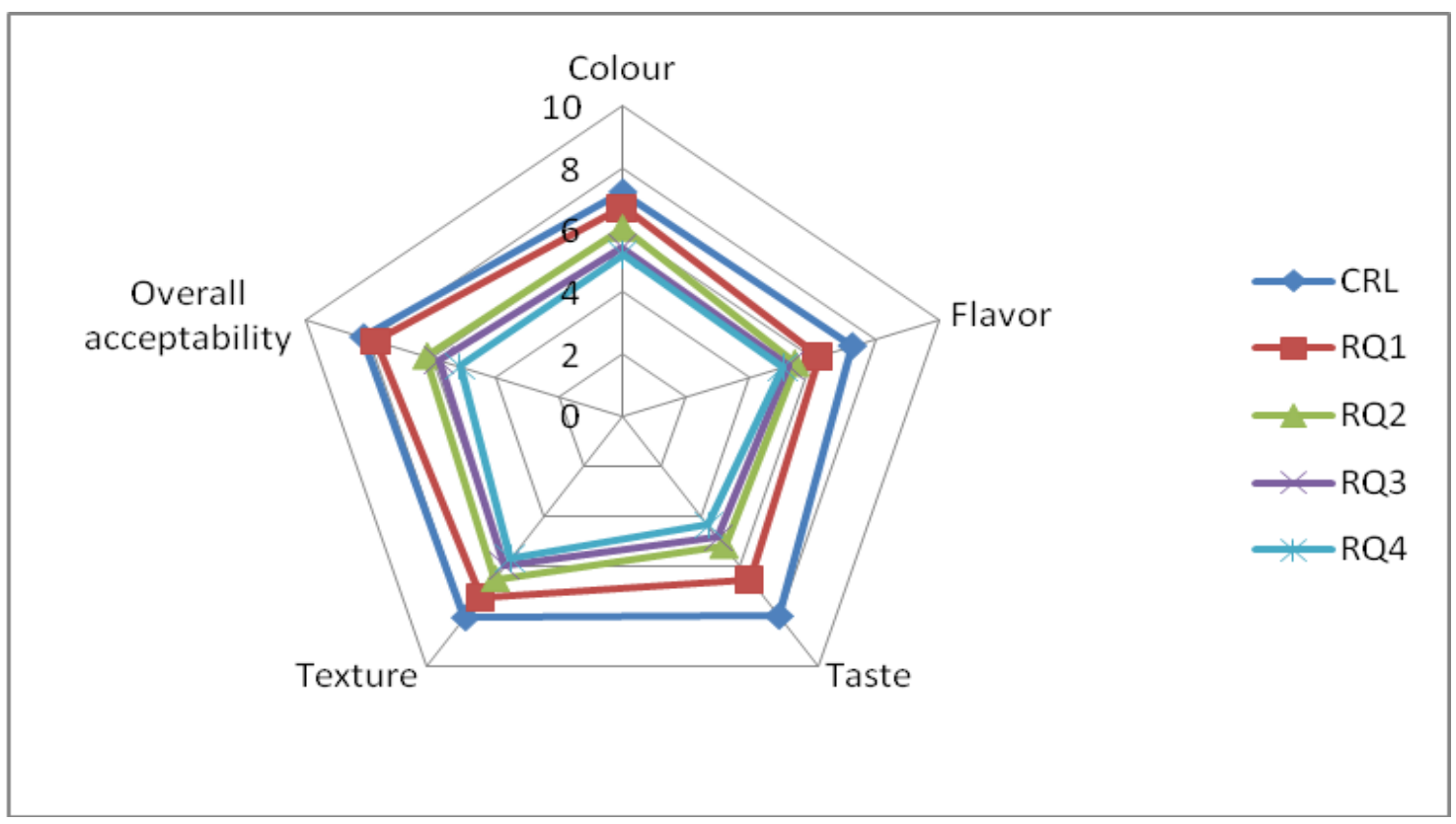

RQ1 - laddu prepared with ragi and germinated quinoa flour (75:25)

RQ2 - laddu prepared with ragi and germinated quinoa flour (50:50)

RQ3- laddu with ragi and germinated quinoa flour (25:75)

RQ4 - laddu prepared with germinated quinoa flour (0:100)

Control: CRL- Ragi laddu.

Fig.4 Sensory characteristics of chapathi prepared with composite flours

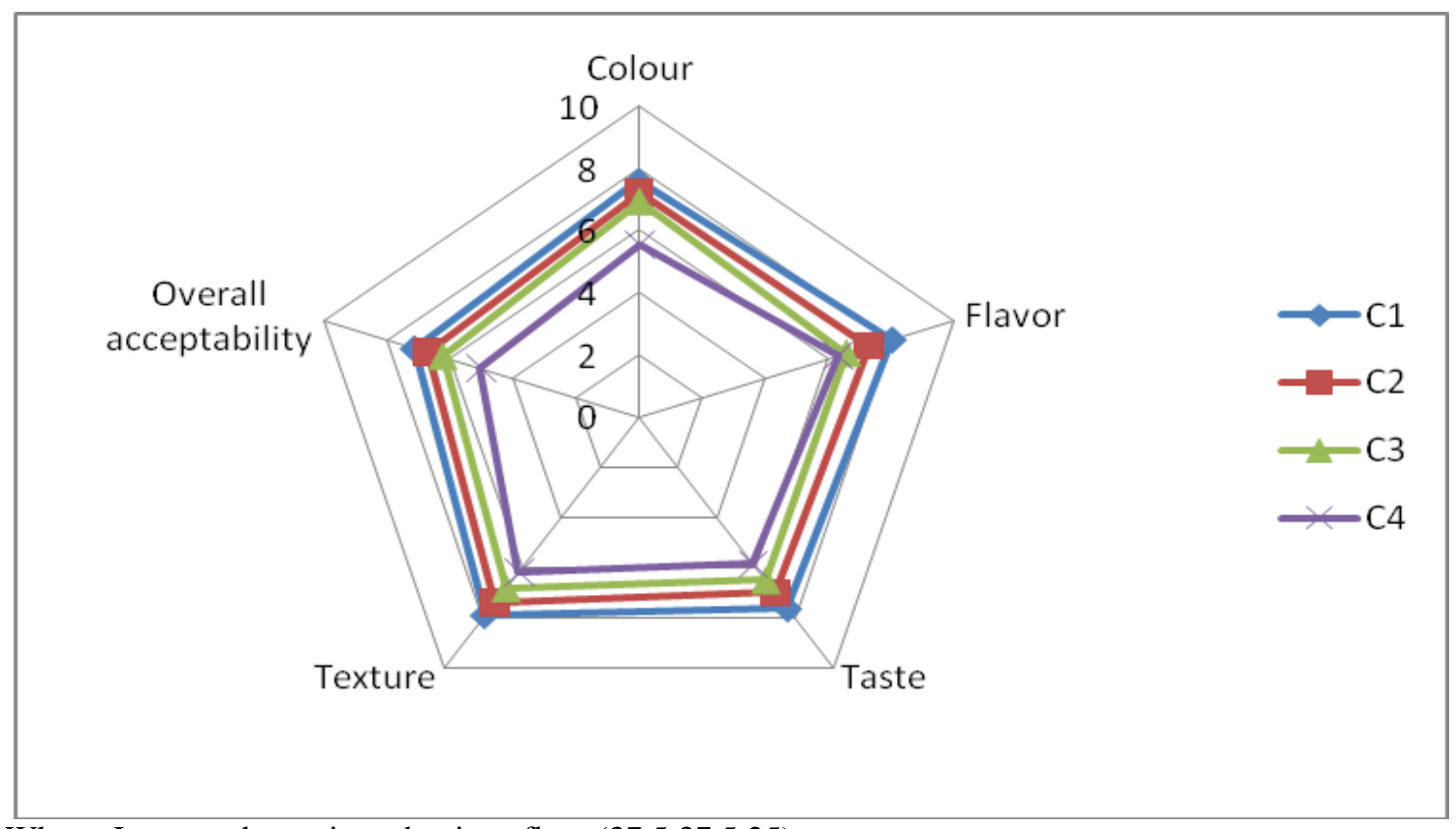

C2 - Wheat, Jowar and germinated quinoa flour (37.5:37.5:25)

C3 - Wheat, Jowar and germinated quinoa flour (25:50:25)

C4- Wheat, Jowar and germinated quinoa flour (12.5:12.5:75)

C1-Control: - Wheat and Jowar chapathi (50:50). 
Table.1 Proportions of the ingredients used in preparation of ladoo

\begin{tabular}{|c|c|c|c|c|}
\hline Combinations & $\begin{array}{c}\text { Ragi flour } \\
(\mathbf{g})\end{array}$ & $\begin{array}{c}\text { Germinated quinoa } \\
\text { flour }(\mathbf{g})\end{array}$ & $\begin{array}{c}\text { Jaggery } \\
(\mathbf{g})\end{array}$ & $\begin{array}{c}\text { Ghee } \\
\text { (tbsp) }\end{array}$ \\
\hline Control sample & 100 & - & 70 & 5 \\
\hline 1 & 75.0 & 25.0 & 70 & 5 \\
\hline 2 & 50.0 & 50.0 & 70 & 5 \\
\hline 3 & 25.0 & 75.0 & 70 & 5 \\
\hline 4 & - & 100 & 70 & 5 \\
\hline
\end{tabular}

Table.2 Proportions of the ingredients used in preparation of chapathi

\begin{tabular}{|l|l|l|l|l|l|}
\hline Combinations & $\begin{array}{l}\text { Wheat } \\
\text { flour }(\mathbf{g})\end{array}$ & $\begin{array}{l}\text { Germinated } \\
\text { quinoa flour }(\mathbf{g})\end{array}$ & $\begin{array}{l}\text { Jowar } \\
\text { flour }(\mathbf{g})\end{array}$ & $\begin{array}{l}\text { Water } \\
(\mathbf{m l})\end{array}$ & $\begin{array}{l}\text { Salt } \\
\text { (tsp) }\end{array}$ \\
\hline 1 & 37.50 & 25.00 & 37.50 & 50 & 0.5 \\
\hline 2 & 25.00 & 50.00 & 25.00 & 50 & 0.5 \\
\hline 3 & 12.50 & 75.00 & 12.50 & 50 & 0.5 \\
\hline Control sample & 50.00 & - & 50.00 & 50 & 0.5 \\
\hline
\end{tabular}

Mean sensory score for taste of chapathi varied from 7.66 to 5.86. Sensory acceptability of chapathi is shown in figure 4 revealed that the control sample $\mathrm{C} 1$ had highest mean score for taste (7.66) followed by C2 (7.00), C3 (6.53) while C4 (5.86) had least mean score for taste.

Mean sensory score for texture of chapathi varied from 7.93 to 6.20. Sensory acceptability of chapathi is shown in figure 4 revealed that the control sample $\mathrm{C} 1$ had highest mean score for texture (7.93) followed by C2 (7.40), C3 (6.86) while C4 (6.20) had least mean score for texture. Texture plays an important role in the selection of product from point of consumer.

Mean sensory score for overall acceptability of chapathi varied from 7.13 to 5.06. Sensory acceptability of chapathi is shown in figure 4 revealed that the control sample $\mathrm{C} 1$ had highest mean score for texture (7.13) followed by C2 (6.73), C3 (6.26) while C4 (5.06) had least mean score for overall acceptability. Incorporation of increasing amounts of germinated quinoa flour reduced the overall acceptability by imparting bitterness and brittle nature of product.

Cheng and Bhat, (2015) reported that the lightness of the composite chapatis displayed a decreasing trend along with the increasing substitution level of jering flour incorporated chapathies. It decreased from 74.07 (control) to 41.29 (100\% substitution level). The reducing acceptability of colour indicates that the composite chapatis are darker in colour at higher levels of substitution. Decrease in mean scores for texture can be attributed to the fact that the composite chapatis become harder when more jering seed flour is incorporated into the formulations. Overall, control wheat chapatis were more acceptable by the sensory panelists followed by wheatjering composite chapatis substituted with 5, 10,15 and $20 \%$ of jering seed flour.

In this study an attempt was made to develop gluten free products by substituting wheat with germinated flour. Although control ragi laddu and chapathi was organoleptically more acceptable than the composite products. The optimized quinoa-based products showed a 
good sensory acceptability revealing their potential for consumption for individuals with celiac disease. These findings suggest the potential of quinoa (processed as flour) for application in mixture with other flours. This indicates that germinated quinoa flour possesses higher potential to act as an alternative functional ingredient in wheat products. The reported work is expected to encourage the utilization of composite flour by blending protein rich pseudo cereal with regular flours in preparation of products.

\section{References}

Caselato-Sousa, V.M., and Amaya-Farfán, J. 2012. State of knowledge on amaranth grain: A comprehensive review. Journal of Food Science. 77: R93-R104.

Cheng, Y.F., and Bhat, R. 2015. Physicochemical and sensory quality evaluation of chapati (Indian flat bread) produced by utilizing underutilized jering (Pithecellobium jiringa Jack.) legume and wheat composite flours. International Food Research Journal. 22(6): 2244-2252.

Falguera, V., Aliguer, N, and Falguera, M. 2012. An integrated approach to current trends in food consumption: moving toward functional and organic products. Food Control. 26: 274-281.

FAO, 2011. Quinoa: An ancient crop to contribute to world food security. FAO Regional Office for Latin America and the Caribbean, Santiago, Chile.

Kahlon, T.S., and Chiu, M.-C.M. 2014. Ancient Whole Grain Gluten-Free Flatbreads. Food and Nutrition Sciences, 5, 1717-1724.

Kahlon, T.S., Avena-Bustillos, R.J, and Chiu, M. M. 2016. Sensory evaluation of gluten-free quinoa whole grain snacks. Heliyon. 2(12).

Mäkinen, O.E., Zannini, E and Arendt, K. 2013. Germination of oat and quinoa and evaluation of the malts as gluten free baking ingredients. Plant Foods for Human Nutrition. 68: 90-95.

Naidu, B.G., Shirke, K. J and Shekhar, A. 2013. A study of a galactogouge and protein rich - multigrain ladoo. International Journal of Food and Nutritional Sciences. 2 (2).

Repo-Carrasco, R., Espinoza, C., Jacobsen, S.E. 2003. Nutritional value and use of the Andean crops quinoa (Chenopodium quinoa) and Kañiwa (Chenopodium pallidicaule). Food Reviews International. 19(1, 2): 179-189.

Yuvarani, S., and Anitha, V. 2016. A study on the consumer acceptance, nutritive value and antioxidant activity of multigrain ladoo. International Journal of Home Science. 2(3): 227-232.

\section{How to cite this article:}

Naga Sai Srujana, M., B. Anila Kumari, K. Uma Maheswari, K.B. Suneetha Devi and Jessie Suneetha, W. 2017. Sensory Quality Characteristics of Gluten-Free Products Prepared with Germinated Quinoa (Chenopodium quinoa Wild). Int.J.Curr.Microbiol.App.Sci. 6(8): 35073514. doi: https://doi.org/10.20546/ijcmas.2017.608.419 